\title{
CONCEPT APPROACH FOR MEASURING SOLIDARITY ECONOMY IN AGRICULTURE
}

\author{
Oleksii GONCHARENKO@1*, Oksana HRYNEVYCH ${ }^{\circledR 2}$, Orlando Petiz PEREIRA@3, \\ Chama Theodore KETUAMAD 4
}

\author{
${ }^{I}$ Department of the Economics, Entrepreneurship and Business Administration, \\ Sumy State University, Rymskogo Korsakova str. 2, 40007 Sumy, Ukraine \\ ${ }^{2}$ Department of General Economics, Faculty of Economics and Business, \\ University of Cadiz, Avenue Enrique Villegas Velez, 2, 11002 Cadiz, Spain \\ ${ }^{3}$ Economics \& Management School, University of Minho, Campus de Gualtar, \\ 4710-057 Braga, Portugal \\ ${ }^{4}$ Faculty of Tropical AgriSciences, Czech University of Life Sciences, Olympijská 1901/7, \\ Prague, Czech Republic
}

Received 04 March 2021; accepted 01 April 2021

\begin{abstract}
Purpose - this work aims to modernize and supplement the methodological approach developed to measure the solidarity economy as a socio-economic phenomenon to determine the reserves and potential for transformation of solidarity at the level of national economies.

Research methodology - the presented research has a conceptual character. For the formation of the algorithm for evaluation used the method of logical generalization and systematic analysis, for search and analysis of descriptive data - thematic analysis of literature sources, for the formation and selection of indicators of solidarity economy of the agricultural sector - content analysis of data characterizing the development of cooperatives in agriculture and their environment functioning, using of secondary data allowed to synthesize existing knowledge, to analyze the current state of solidarity of the agricultural sector. Scientific articles of the Scopus database, publications of web portals of the solidarity economy (SE), and information from the Eurostat methodology were used as sources.

Findings - the research contributes to increasing the visibility of the positive effects of the SE in the agricultural sector to improve its social and political recognition.

Research limitations - the research is limited by the chosen methodological approach that makes it unable to conduct an expansion and development of a system of qualitative indicators of estimation of solidarity economy with a specific focus on agriculture(SEAGro), which can be used for the development of the classification of indicators of SERagro, research of influence of solidarity of farmers on sustainable development of a regions.

Practical implications - measuring the scale and impact of SE in the agro sector will help to establish the socio-, ecological, and economic effects for Sustainable Development in general and contribute to further institutional and policy transformations.

Originality/Value - not only quantitative and qualitative indicators of SE as a socio-economic phenomenon were studied in order to determine the reserves and potential of solidarity transformations, but also developed a scientific and methodological approach to assessing the solidarity of the agricultural.
\end{abstract}

Keywords: solidarity economy, agricultural sector, cooperatives, national economy, sustainable development.

JEL Classification: Q01, Q13, F63.

Conference topic: Business Processes: Development, Digitalization, Social Responsibility.

\section{Introduction}

In 2019 and 2020, the world faced the COVID-19 pandemic as a threat that is unparalleled in its scale and psychological perception over the past 100 years. It is especially unfortunate to realize that none of the economic systems and the level of development of society was ready for this challenge. The general problem rea can be identified as such

\footnotetext{
"E-mail: o.goncharenko@econ.sumdu.edu.ua
}

(C) 2021 Authors. Published by Vilnius Gediminas Technical University. This is an open-access article distributed under the terms of the Creative Commons Attribution (http://creativecommons.org/licenses/by/4.0/) License, which permits unrestricted use, distribution, and reproduction in any medium, provided the original author and source are credited. 
that in the context of the problems of limited movement of goods and human capital and periodic closure of borders was to ensure food security, including for European countries. Food supply is directly linked to the agricultural sector. There is an urgent need to expand and establish relations between the participants of the agricultural sector, their closer association, and cooperation to meet possible commodity imbalances arising from the pandemic. European countries are on the path to solving social, economic, and environmental problems. However, some positive effects of solidarity of society in different countries are already visible (Hrynevych \& Goncharenko, 2018). Therefore, there is a need to disclose such scientific issues in the study of solidarity between farmers in the agricultural sector during and after the pandemic, which is an urgent challenge today. First of all, to conduct a comparative analysis of changes in the level of farmers' cooperation, it is necessary to explore a niche for the implementation and dissemination of the principles of solidarity in the context of sustainable development, where cooperatives are seen as a tool. Cooperatives and Solidarity play a special role for both producers and consumers. By combining economic and social goals, cooperatives can become a key element of farmers' solidarity in creating employment opportunities, helping to mitigate and adapt to the effects of climate change, and providing affordable opportunities to poor rural and urban consumers, including women and youth. Due to the limited methodological approaches to assessing solidarity in the agricultural sector, the following scientific question arises in creating a system of indicators that will characterize the level of solidarity in the agricultural sector and build a methodology for their integration into the aggregate index.

The article aims to create a conceptual information base for the future assessment and comparison of the solidarity of the agricultural sector to reduce uncertainty in decision-making on sustainable development. The scientific task for this work is to adapt and supplement the methodological approach developed in Hrynevych and Goncharenko (2018). This study was conducted in the context of the general hypothesis promoted by supporters of the solidarity economy that solidarity helps to overcome and prevent socio-economic and political crises (Arruda, 2004; Allard et al., 2008).

In general, it is very difficult to approach the issue of any assessment of solidarity in different countries, as the very definition of solidarity in socio-economic systems can be interpreted differently even by citizens of the country, i.e. what is meant by solidarity in the north can be interpreted differently in the south. If we look at the map of solidarity formations, we can see that the southern parts of the regions are more represented by elements of the solidarity economy. This is primarily due to the mental characteristics of different people. However, having defined the basic concepts earlier, we can move on to an overview of the notions of quantitative analysis of the level of solidarity. It should be noted that the concept of qualitative measurement of economic solidarity is a possible topic of a separate study.

Modern challenges to the development of society on a global scale are primarily due to the heterogeneity of the needs of its various parts. Thus, the societies of third world countries are aimed at solving mainly the material needs of their existence, while the "more developed" societies of developed countries, which have mainly solved the material needs of their existence, make great efforts to solve environmental, economic and social problems. However, there is a common feature in both parts of the world society - a crisis of self-identification in society, which is expressed in dissatisfaction with the redistribution of public goods and the derivative consequences of this process. This issue gives rise to a broad public debate on ways of self-preservation and the search for new vectors of development of nations and states, which is presented in the works of (Miller, 2013; Quiroz-Niño \& Murga-Menoyo, 2017; Utting \& Dijk, 2014). It remains obvious that the prevailing modern economic system is not able to address the socio-ecological and economic challenges of society. Violation of the former system of world order creates a demand for the formulation of a new strategic worldview and a project for the effective development of society.

Some scientists (Allard et al., 2008; Kawano, 2013) consider the solidarity economy as a way to overcome these crises. Despite a large number of studies on this topic, there are a number of issues that are not given sufficient coverage. Thus, we consider it necessary to study the quantitative and qualitative indicators of solidarity economy (SE) as a social phenomenon to determine the reserves and potential for solidarity transformations. In this context, in our opinion, the task of developing a scientific and methodological approach to assessing the solidarity of the national economy is especially relevant.

For a deeper understanding of the concept of solidarity economy, consider the theoretical justification of this concept. Authors (Arruda, 2004; Reintjes, 2004) understand SE as an activity of production, distribution, and consumption of goods, which contributes to the democratization of the economy based on civic obligations at both local and global levels. This type of activity is carried out in various forms of management, on all continents of the earth, and covers various forms of labor organization, which are used by the population to create benefits in the spirit of reciprocity and solidarity that connects individual interests with collective interests. In this sense, the solidarity economy is not a sector of the economy, but a general approach that includes initiatives in most sectors of the economy. Let us agree with the author M. Arruda in his conceptual definition of solidarity economy, but offer a more user-friendly interpretation without changing the author's essence and note that the SE is an economic activity organized for sustainable development of society, aimed at meeting the needs of and desires of its members, joint management of inexhaustible nature management and nature conservation at different levels of the socio-economic system - house, community, district, district, ecosystem, country, planet. It is an ethical, reciprocal, and cooperative way of consuming, producing, financing, exchanging, communicating, learning, developing, which promotes a new way of thinking and living. 
The formation of a solidarity economy is a long-term process in which there are signs of cyclicality. The experience of previous periods, namely the economic crisis in Spain during the civil war in 1936, the economic crisis in Chile in 70-80, the rapid development of solidarity in Argentina and Brazil in the mid-20th century, the German economic miracle in 1950-the 1960s showed that the most effective ways to overcome the effects of the economic crisis are a partnership in the organization of joint activities, the distribution of benefits according to well-founded criteria, as well as their collective fair consumption.

\section{Literature review}

This study is based on and is a continuation of the work (Hrynevych \& Goncharenko, 2018), in which a methodological approach to assessing the solidarity of national economies is developed. The study is based on key areas of development of the solidarity economy of different countries. In Hrynevych and Goncharenko (2018) was proposed an algorithm and a system of quantitative indicators for measuring the solidarity economy as a socio-economic phenomenon to determine the reserves and potential for solidarity transformation at the level of national economies of different countries. This study supported the research algorithm discussed in Hrynevych and Goncharenko (2018), however, the mechanism for scoring indicators based on the minimax method was improved and an adapted methodological approach with a supplemented and changed system of indicators of the sectoral nature of agro-industry solidarity was proposed.

During the analysis of the publications related to the assessment of the level of manifestations of the Solidarity Economy were reviewed the most notable works. The paper (Botton \& Joanpere, 2015) reflects on some appropriate approaches, indicators, and methods of measuring solidarity to extract those useful contributions to build indicators of the social impact of solidarity. However, it should be noted that the focus is on the social component, and the economic and environmental components of solidarity are insufficiently studied.

How can solidarity be assessed in general? Most authors consider the answer to this question through the identification of various effects due to solidarity. This approach raises some problematic aspects related to the availability of quantitative and qualitative characteristics of solidarity.

Due to the lack of a statistical information system at the international and national levels, some actors are beginning to create their assessment of solidarity in their practice. Also, more and more authors are focusing on how to evaluate solidarity activities and how to create the necessary parameters to measure the improvements they contribute. According to the authors Ratcliffe and Newman (2011), social solidarity requires methods and indicators designed to measure the improvement of people's lives, as well as methods and indicators developed specifically for each project.

Numerous scientific publications consider the cross-disciplinarity of solidarity. Thus, the authors (Abela, 2004; Lichterman, 2015) address issues of solidarity through the prism of morality and religion, and (Friedman \& Gostin, 2017) investigate solidarity in health care, which became extremely relevant during the pandemic. Continuing the analysis, a group of authors (Berman \& Phillips, 2004; Chuang et al., 2013) explore solidarity through social cohesion and explore its interrelationships with various spheres of life, such as individual health. They hypothesize that social cohesion was associated with individual self-esteem after control of individual characteristics.

The authors (Berman \& Phillips, 2004) focus on three dimensions of solidarity: social relations, integrative norms and values, and identity. The authors also use modern tools such as the World Values Survey (WVS) or the UN Declaration of Human Rights at various levels of human existence.

The connection and compliance of the solidarity economy with the goals of sustainable development, as the main reference point for the development of strategic plans and policy actions of the European Union (Lee, 2020; Mozas Moral, 2019; United Nations Research Institute for Social Development [UNRISD], 2019; Utting, 2018), is currently being studied. Thus, the authors in these works determine that despite the internal inconsistencies and contradictions of the 17 goals of sustainable development, there is a direct impact on the results of joint ventures. For example, the authors (Villalba-Eguiluz et al., 2020) empirically identified the convergence of solidarity-oriented projects and goals 2 (hunger and food), 5 (gender equality), 8 (economic growth and employment), and 12 (consumption and sustainable production models).

Researchers have studied approaches to measuring the economic impact of solidarity (Reyes, 2005; Roy \& Ottaviani, 2016). Summarizing their work, the authors emphasize the creation of vertical models of networks of solidarity entities and propose social empowerment of solidarity through policy development, which will include the importance of understanding the regional context and will drive change in the economic sphere, namely equal distribution of wealth.

Other authors (Botton \& Joanpere, 2015) emphasize the need to use high-quality or mixed assessment systems that allow a deeper and more direct approach to our social experience, taking into account different human backgrounds and gender.

The search query "Solidarity and Agriculture and Evaluation" give Google Scholar a result of more than 60,000. Most of them are usually published by some mention and the attitude to measuring the level of solidarity in agriculture is very remote. 
There are several articles aimed at assessing solidarity in the case of studies based on real experience, and each of them is presented from different approaches, focuses, or objects of research. In this article, we try to supplement this list of literature with a new methodological approach, with its features on the researched problem. For some of the studies that are the subject of the analysis, most of them focus on identifying the impact of solidarity organizations on community development.

This paper (Bots et al., 2010) presents the social behavior of subjects in the context of resource allocation (water) in such a way that different forms of solidarity can be identified and measured.

Most often, the measurement of solidarity is described in a certain direction, such as the provision of food as in (Malak-Rawlikowska et al., 2019), which does not provide a comprehensive assessment. Or, as a rule, the descriptive nature of the elements of agricultural solidarity without a consolidated comprehensive assessment is considered (Lyson, 2012). Or the estimation of the basis of the solidarity economy as social capital (Svendsen \& Svendsen, 2000), which is seen as a new factor of production, is productive because it increases the level of trust in society and allows more transactions without coercion.

Given the objectives of the article, consider the main authors, who to some extent describe the assessment of solidarity in agriculture. As mentioned earlier, one of the main manifestations of solidarity in agriculture is farmers' cooperatives. Therefore, most authors consider this issue through the evaluation of the activities of farmers' cooperatives.

The authors (Madarasz et al., 2013) assess the impact of cooperatives on employment in agricultural regions in Slovakia and conclude that the number of their employees is constantly declining. However, a case study showed that cooperatives still have a large impact on employment for their regions. Transformed cooperatives are quite conservative, and they are not open to new types of agriculture, such as rural tourism and environmental protection. Thus, they do not support the development of rural areas and the creation of new jobs in rural areas.

The study (Banaszak, 2008) evaluated the management efficiency of a sample of Polish farmers' cooperatives in terms of joint marketing of products produced individually by their members. The conclusions were that leadership, previous business acquaintances, an initial selection of members, and the number of members have a significant positive impact on the probability of success of the studied organizations.

Thus we can make the following conclusions:

1) There is a need to assess the impact of solidarity on agricultural development, as this area is poorly studied in contrast to health, economics, employment, and social integration.

2) There is no system of indicators and specific criteria for measuring the solidarity of agriculture. After reviewing the literature and evaluation indicators, there is a need to develop and conceptualize them at different levels of management.

3) Most solidarity analyzes are currently conducted from a personal and subjective point of view and there is still no research suggesting how to assess the social, economic, and environmental impact of solidarity manifestations created by organizations and institutions. There is also no tool or some criteria to develop standard indicators for assessing socio-economic improvements caused by actions based on solidarity. This study attempts to assess the level of solidarity in agriculture more systematically.

4) As already mentioned, measuring the impact of solidarity is a fundamental requirement that is beginning to be included in global and European societal challenges, such as the analyzed UN Sustainable Development Goals or the European Pillar of Social Rights. Therefore, the method proposed in this paper will be interesting to consider.

\section{Research methodology}

Since the papers conducted fundamental research to develop knowledge about the agricultural sector's social and solidarity economy, it used methods of analyzing the literature review of various sources and databases (Socioeco. org, RIPESS, and others) and groups indicators of the European Union government statistics. The research is also aimed at highlighting the main aspects of the insufficiently studied methodology for assessing the development of the agricultural sector's solidarity economy and should become the basis for quantitative assessment. The study uses a method that involves a graphical representation of the level of assessment of the agricultural sector's social solidarity economy. For reliability and validity in selecting the system of indicators, the authors used qualitative analysis methods. Indicators were selected according to several criteria: the ability to quantify and/or how fully the indicator characterizes the selected pillar in one time reporting period in different countries; whether it is possible to manage this indicator at the expense of the organizational and managerial tool. Also, the indicators were made comparable by bringing them into relative form based on the method of scoring. This technique was intended for conducting cross-sectional studies to collect data at one point in time. At the national and global levels, particularly in developing countries, there is insufficient coordination of statistical activities related to measuring the assessment of the solidarity economy in agro-industry (SEAgro), from data collection, processing, and dissemination to standardization of statistical methods, classifications, and definitions. However, there are several examples of methods, tools, and data that can be used to measure and evaluate SEAgro, in particular (UNRISD, 2018): 
- Eurostat data on cooperatives, mutual organizations, and the associative sector in the European Union;

- CIRIEC data for mapping the social economy in the European Union;

- Johns Hopkins University data on the non-profit and voluntary sectors;

- Satellite data of CIRIEC cooperatives and mutual societies;

- Social Returns on Investment, first documented by the Roberts Enterprise Development Fund;

- Logical Framework Approach proposed by the Expert Group on Social Entrepreneurship;

- Data of the European Commission for mapping social enterprises in the European national context;

- Third Sector Impact project (TSI).

It is worth mentioning two caveats regarding this typology. First, classifications are not mutually exclusive; second, methods, measurement tools, and data often use the same measures and indicators that reflect and interpret both the scale and impact of the SE.

In developing a scientific and methodological approach to assessing the solidarity economy in the agro-industry (SEAgro) the authors followed the logical algorithm shown in Figure 1.

This algorithm (Figure 1) consists of the main stages, which are comprehensively and logically aimed at achieving the objectives of this article.

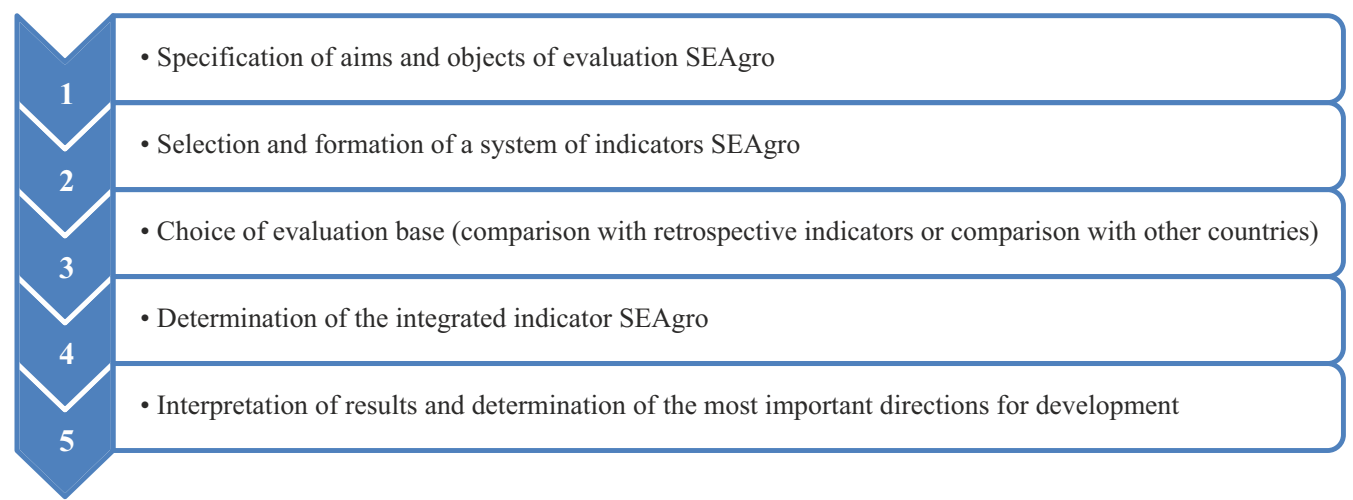

Figure 1. Methodological approach to assessing the solidarity economy in the agro-industry (SEAgro) (source: elaborated by authors in relation to Hrynevych \& Goncharenko, 2018)

\section{Results}

Measuring the scale and impact of SEAgro will help establish the effects for SE in general and contribute to further institutional and policy transformations. An important focus is to increase the visibility of the positive effects of SE in the agricultural sector to improve its social and political recognition. The SEAgro assessment will also encourage the mobilization and support of governments and other social influence stakeholders.

Using short theses in (UNRISD, 2018) in this article to form a methodology for assessing SEAgro was taken into account the concept of scale, scope and impact of solidarity. It should be noted that the main elements have different meanings, depending on the conceptual framework and methodologies used to measure them.

The rating scale refers to the various dimensions of SEAgro, including the number and size of organizations, as well as the coverage of their activities (local, regional, national, global). The scope concerns the diversity and range of SEAgro organizations and their activities.

Measuring the scale of SEAgro involves consideration of indicators in relative and absolute terms. Given the requirement for their comparability between different countries.

In this study, scale measurement includes both scale and scope. Thus, measured:

- counting the number of SEAgro organizations;

- the size of SEAgro based on job creation;

- the value of SEAgro elements and/or products (i.e. contribution to GDP).

The SEAgro level is measured in a year.

The logic of forming a conceptual system of indicators and its components for the assessment of SEAgro was based on the model of The Network Readiness Index (Dutta \& Lanvin, 2020). Based on the analysis of literature sources and basic research, a system of indicators was formed to assess the level of SEAgro by country. The SEAgro valuation index is formed of four components - pillars (Figure 2).

The reasoning of the pillars and sub-pillars of the redesigned SEAgro model can be summarized as follows.

Financial and investment support - the pillar of SEAgro assessment $\left(\right.$ SEAgro $\left._{\text {fin-invest }}\right)$.

Financial flows of agro-industry are the basis for improving the efficiency of its management. It is the presence of a wide range of financial instruments that indicates the development of a particular sector of the economy. 


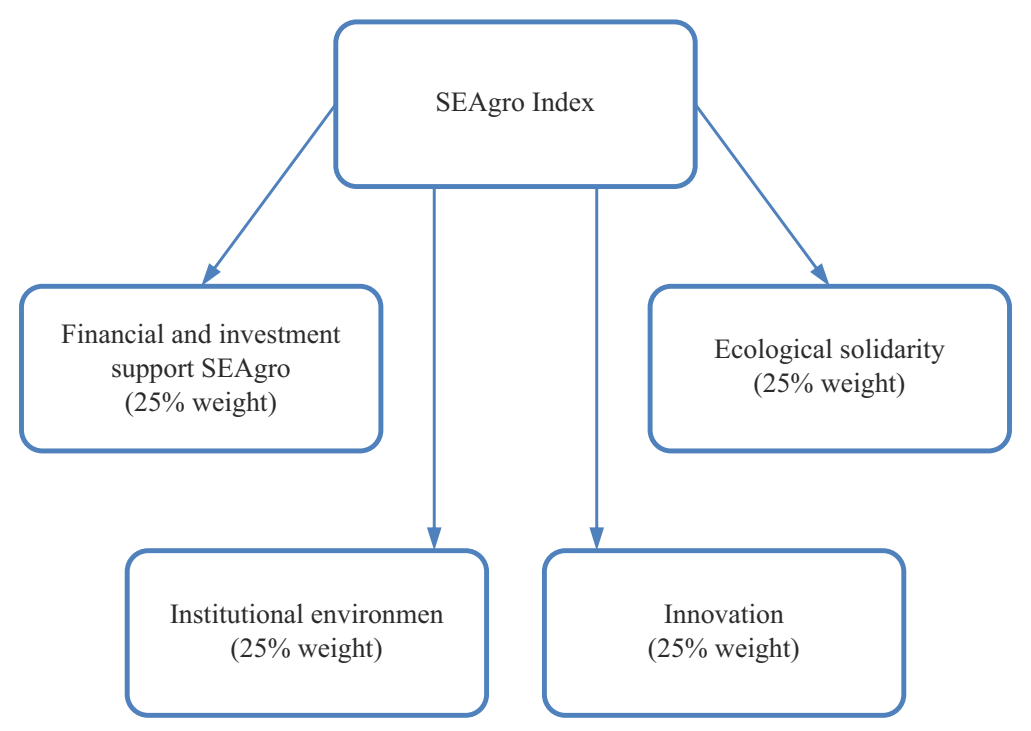

Figure 2. Main pillars composing SEAgro index

(source: elaborated by authors in relation to Hrynevych \& Goncharenko, 2018)

The financial activity of entities belonging to solidarity entities in the agro-industrial sector as creators of added economic value and the volume of such activity are key indicators in assessing the level of SEAgro. In turn, the volume of investments in this sector has a significant impact on ensuring the profitability of Solidarity Agricultural Enterprises. It is the investment that ensures the transition to a qualitatively new technological level, as in the case of Industry 4.0. Therefore, the following qualitative and quantitative indicators of the financial and investment block were selected for evaluation:

- Share of Government grants for cooperatives and other solidarity groups in the total number of grants at the national level. Criterion - share maximization;

- Part of traditional loans and equities, and proceeds from assets and budget surpluses. Criterion - share maximization;

- Social impact bonds in joint ventures of the agricultural sector. Social impact bonds are a common practice by which the government (often a municipality) can replace public services provided directly by the state or public administration paid for directly by the state. Instead, it enters into a tripartite agreement with potential private investors, joint and several agricultural enterprises, and government agencies that want to jointly invest and provide services. The state reimburses the investor and solidarity agricultural enterprises for interest if the service is properly provided (judging by the results). If successful, the joint venture reinvests its share of profits to expand or consolidate its activities (UNRISD, 2021). For example, a service may consist of accompanying unemployed workers in search of work, which, if they do so, may save public resources in the form of unemployment benefits. Criterion - increase in number;

- Volumes of impact investing in joint ventures of the agro sector. Effective investment (or social venture capital) refers to investments directed at companies, organizations, and funds to create significant social and/or environmental impacts along with the financial return on investment (UNRISD, 2021);

- Share of funding for socially-oriented research projects in the agricultural sector of the total funding. The criterion is an increase in the number;

- Crowdfunding. The volume of investments through crowdfunding platforms in joint ventures of the agricultural sector;

- Volume of operations based on crypto currencies in the agricultural sector. Another manifestation of solidarity in the investment component of the economy is the emergence and development of crypto currencies.

However, due to the lack of clear regulation of this currency by many countries, it is impossible to use indicators of the development of crypto currencies to assess the SE in terms of individual countries. We believe that to assess this aspect from the point of view of the SE it is necessary to use not quantitative, but qualitative indicators, such as the degree of perception of crypto currencies at the institutional level in the country.

Innovative SEAgro - pillar of SEAgro assessment (SEAgro innov $_{\text {in }}$ ).

This block can be divided into two sub-blocks: the cost of innovative technologies for joint ventures in the agro-industrial sector and organizational innovation entities in the agricultural sector. Thus, solidarity is also manifested in the formation of specific physical or virtual spaces, the purpose of which is to create fundamentally new knowledge, by attracting collective efforts on a solidarity basis and obtaining evaluated results of their activities. Indicators that characterize the level of development in the assessment of SEAgro innovation can be: 
- Share of the cost of innovative technologies of solidarity and social enterprises of the agricultural sector in relation to the total cost of technology;

- Number of entities to support and promote innovations (incubators, hubs, etc.);

- Ranking of the country on the indicator "Human Capital and research" according to the International Innovation Index.

Ecological solidarity - pillar of SEAgro assessment (SEAgroecolog).

The logic of the inclusion of the ecological unit in assessing the level of SE Agro is as follows. Human's treatment of nature in the last century has led to catastrophic consequences. Humans' understanding of themselves as a part of the natural environment is in solidarity with nature. Therefore, the level of solidarity, in this case can be assessed by generalized indicators, such as environmental footprint, energy intensity, dematerialization. We believe that the reduction of the eco-destructive burden on nature indicates the strengthening of solidarity of society both internally and externally. Due to the existence of a large number, we choose and use the main common generalizing indicators:

- Ecological footprint of the country's agricultural sector per person. An ecological footprint per person is a general ecological footprint of a country divided by the total population of the country. To live on the resources of our planet, the ecological footprint around the world must be equal to the available biocapacity per person on our planet, which today is 1.7 global hectares (Global Footprint Network, 2020). Thus, if a country's ecological footprint per person is 6.8 global hectares, its citizens demand four times more resources and waste that our planet can regenerate and absorb in the atmosphere(Global Footprint Network, 2020). Criterion - reduction of the indicator.

- Energy intensity of the agro-industrial sector. The energy intensity of the agricultural sector can be calculated as the ratio between the gross domestic energy consumption of the agricultural sector and its gross domestic product for a given calendar year. It measures energy consumption in the economy and overall energy efficiency. Gross domestic energy consumption and is calculated as the sum of gross domestic consumption of five types of energy: coal, electricity, oil, natural gas, and renewable energy sources. Since gross domestic consumption is measured in kgoe (kilograms of oil equivalent) and GDP is 1,000 euros, this ratio is measured in kgoe per 1,000 euros. The criterion is a decrease in the indicator.

- Dematerialization of the country's agricultural sector. This indicator can be measured Domestic material consumption per capita of the country. The indicator is defined as the total amount of material that is directly used in the economy and is equal to the direct input of materials (DMI) minus exports. DMI measures the direct flow of materials for use in the economy. DMI is equal to domestic production (DE) plus imports. The average population is used to calculate the per capita indicator (Eurostat, 2021).

Institutional environment - pillar of SEAgro assessment (SEAgroinst).

To assess the solidarity of the agro-industrial sector in terms of institutional support, it is proposed to use data on enterprises based on the principles of solidarity economy in the agricultural sector and infrastructure elements designed to provide organizational support for solidarity enterprises. Quantitatively, the level of solidarity in this block can be determined by the following indicators: the number of solidarity enterprises in the agricultural sector, organizations, etc., the number of people involved in such organizations, gross income (turnover) of such enterprises.

- Number of formal institutional set-ups (governmental organizations and structures designed to support, implement, or otherwise promote the development of social and solidarity enterprises);

- Number of legislative acts that in one way or another regulate the activities of social and solidarity enterprises and organizations;

- Informal arrangements between government and actors associated with SEAgro;

- Agricultural cooperatives;

- Agricultural non-profit organizations of various forms, including associations engaged in economic activity;

- Agricultural mutuals, which are typically formed to organize finance-related activities, such as saving and insurance schemes;

- Agricultural foundations, which are commonly understood as a tool for one or more donors to assign resources to accomplish public interest projects without seeking profits;

- Social Agricultural Enterprises, which are often required to meet certain criteria concerning their social, environmental or community objectives and use of surpluses or profits.

Therefore, to assess the SEAgro countries, we propose to use the construction of a graph-analytical modeling relation to (Hrynevych \& Goncharenko, 2018). This study, it was adapted using the above groups of indicators. As a result of its construction, we obtain a visual model in the form of a polygon, which clearly illustrates the level of development of the country's SE compared to others. The shape of the polygon depends on the number of vectors Thus, in our study, as already mentioned, the following SE vectors were identified:

The algorithm for constructing a graph-analytical model for estimating SEAgro used in relation to (Hrynevych \& Goncharenko, 2018): 
1. Indicators $\left(a_{i j}\right)$ for each vector are presented in the form of a table, where the rows are the numbers of indicators $(i=1,2,3 \ldots n)$, and in the columns the countries as estimated $(j=1,2,3 \ldots m)$.

2. Each indicator is normalized to a 1-to-7 scale by minimum-maximum scaling method (Little, 2013):

- A case when a lower value indicates a worse outcome:

$$
R_{i j}=\frac{6 *\left(a_{i j}-\min \mathrm{a}_{i j}\right)}{\left(\max a_{i j}-\min \mathrm{a}_{i j}\right)}+1,
$$

where: $\min a_{i j}$ - sample minimum indicator $\left(a_{i j}\right)$ for vector; max $a_{i j}$ - sample maximum indicator $\left(a_{i j}\right)$ for vector.

- A case when a higher value indicates a worse outcome:

$$
R_{i j}=\frac{-6^{*}\left(a_{i j}-\min a_{i j}\right)}{\left(\max a_{i j}-\min a_{i j}\right)}+7 .
$$

3. Finding the sum of indicators $\left(R_{i j}\right)$ according to the formula (PSEagro $\left.{ }_{z}\right)$ :

$$
\mathrm{P}_{z}^{\mathrm{SEagro}}=\sum_{i, j}^{n, m}\left(R_{i j}\right)
$$

where: $z$ is the name of the vector of SEagro estimation of each country.

4. Transform the $\mathrm{P}_{z}$ SEagro into the length of the vectors $\left(\mathrm{V}_{z}^{\text {SEagro }}\right)$, which determines the length of the vertex of the polygon. The formula for calculating the vector $\mathrm{V}_{z}^{\text {SEagro }}$ is as follows:

$$
\mathrm{V}_{z}^{\text {SEagro }}=\frac{\mathrm{P}_{z}^{\text {SEagro } * 100}}{\max \mathrm{P}_{z}^{\text {SEagro }}},
$$

where: $\max \mathrm{P}_{z}$ SEagro - sample maximum of sum of indicators $\left(R_{i j}\right)$ of each country.

5. Determining the length of all vectors, draw a polygon and draw the appropriate conclusions.

6. To determine the index SEAgro level of the country, it is proposed to determine the area obtained as a result of constructing polygon vectors.

The area of the polygon of the SEAgro level of the country can be calculated by the formula:

$$
\mathrm{S}_{\text {SEAgro }}^{m}=\frac{1}{2} \sum_{z=1}^{n} V_{z} * V_{z+1} * \sin \alpha_{z /(z+1)},
$$

where: $\mathrm{V}_{z}$ and $\mathrm{V}_{z+1}$ the length of the adjacent $z$-th and $(z+1)$-th components of the country's SEAgro assessment; $\alpha_{z /(z+1)}$ - angles between adjacent $z$-th and $(z+1)$-th component. The angles between adjacent components are calculated by the formula:

$$
\alpha_{z /(z+1)}=k_{v z} * 360^{\circ},
$$

where: $k_{v z}$ - the weight of the first ( $z$-th) component of two adjacent.

7. Depending on the objectives set at the beginning of the analysis, it may be appropriate to segment countries by polygon area.

The results of the calculation of the country index can be compared according to income group (High-income countries, Upper-middle-income countries, Lower-middle-income countries, and Low-income countries), countries by region (Africa, Arab States, Asia \& Pacific, CIS, Europe, The Americas). For instance, it is also important to determine the strongest and weakest indicators of the country. To visualize the obtained results, it is recommended to plot the values of the obtained indices by countries on the map.

Thus, the obtained graph-analytical model clearly demonstrates the leadership of countries in the field of SEAgro. The main thing is that it helps to identify the main priority ways of SEAgro development in comparison with the leading countries. Also, the shape and scale of the polygon (namely its proximity to the correct shape, i.e. square) allow determining the level of its balance by the components of each vector. That is to determine which of them is developed to a greater or lesser extent. That allows making decisions on the development in a different direction of SEAgro of the country. 


\section{Comments and discussion}

We consider it necessary to express our comments on this technique in relation to (Hrynevych \& Goncharenko, 2018).

1. This technique is not an exhaustive assessment of the level of development of SEAgro of different countries. Given the existence of many phenomena and processes in the system of economic solidarity, which are not identified as indicators and their statistical accounting is not conducted, this methodology cannot cover all indicators and be full-scale. In particular, it can be supplemented by other vectors that represent the directions of development of SEAgro. However, we believe that it can become a basis for research in theory and practice.

2. The issue of including indicators in this methodology is debatable. Due to the large number of heterogeneous indicators that directly or indirectly characterize the level of development of SE, the authors included in the system indicators first on the principle of availability of data in official statistics, and secondly - their reflection of SE trends. Despite the presence of both the resulting and infrastructural indicators, we believe that this technique is informative.

3. The lack of some data can significantly affect the results obtained. In this study, the calculations were not performed to test the methodology, it is a task for further research and the involvement of a wider range of experts.

4. In the calculations, all indicators were considered equivalent to be taken into account in each vector, although the coefficients of importance of indicators in the integrated assessment can be introduced.

\section{Conclusions and directions of further research}

In solidarity economy theory, agricultural cooperatives and solidarity entrepreneurs can facilitate sustainable development by integrating social, economic and ecological goals. Solidarity agricultural elements can play a significant role in creating a more favourable labour market (especially in a pandemic and in the context of Industry 4.0), prevent climate change, and streamline agricultural supply chains from producer to equal consumer rights to women, youth, and the vulnerable segments of the population. Thus, solidarity agricultural enterprises are essential to the success of sustainable development and for solving community problems.

This paper had made a theoretical method approach to assessing the level of solidarity of different countries' agricultural economies. The purpose is to create an information basis for decision-making at different management levels on sustainable development of countries and regions. The essence of this approach is to determine the integrated index of agricultural solidarity of different countries. The general index is calculated based on four blocks of indicators: financial and investment, innovative, environmental solidarity and institutional. These sections, in turn, consist of indicators that characterize each direction from different angles. Depending on the specific objectives of empirical research, the composition of indicators for each block may vary. The calculation of the index used a scoring scale and the principle of comparing indicators by country.

As already mentioned, and the authors support this thesis, the solidarity economy of agriculture is closely focused on achieving the goals of sustainable development, especially in the context of one of the most important goals "zero hunger", which aims to end hunger, achieve food security and promote sustainable agriculture (Asamblea General de la Union Europea, 2015). Also, in the framework of the pillars "Financial and investment support" and "Innovation", we can see the focus on goal 8 , aimed at sustainable economic growth, decent work, employment and equality, as well as innovation (Asamblea General de la Union Europea, 2015). Pillar "Ecological solidarity" is closely intertwined with the achievement of goals $6,7,11,12,13,15$ - clean water and sanitation, affordable and clean energy, sustainable cities and communities, responsible consumption and production, climate action, land life (Asamblea General de la Union Europea, 2015). Finally, the pillar "Institutional environment" aims to achieve goals 16 and 17 - to promote peaceful and inclusive societies for sustainable development, to ensure access to justice for all, and to build inefficient, accountable, and inclusive institutions at all levels (Asamblea General de la Union Europea, 2015).

The data and results obtained after using this approach can be applied in the development of policies and strategic plans for sustainable development. It should also be noted that the justification revealed shortcomings in the system of collecting statistical information on the indicators of the solidarity economy in agriculture for possible calculations, so suggestions can be made to improve the system of European Statistics.

The directions of further research are expansion and development of the system of qualitative indicators of SEAgro assessment, development of classification of SEAgro indicators, research of the impact of farmers' solidarity on sustainable development of the region, conducting a survey among farmers to recommend governmental and non-governmental organizations on SE and sustainable development strategy.

\section{Funding}

This work was supported by the Czech government support provided by the Ministry of Foreign Affairs of the Czech Republic, which allowed this scientific cooperation to start within the project "AgriSciences Platform for Scientific Enhancement of HEIs in Ukraine". 


\section{Contribution}

OG contributed to the development of the main idea, conception, analysis and interpretation of literature, as well as the writing of the manuscript.OH participated in the design and revising it critically for important intellectual content. OPP preparation of the methodological base of Solidarity Economy, writing of the introduction, conclusions, general recommendations on the methodology of SEAgro assessment.CTK substantiation of SEAgro assessment methodology with agro-industrial complex, analysis and proposal of methodological assessment components, formula formation. We believe the manuscript represents honest and valid work.

\section{Disclosure statement}

Authors declare that they have no conflict of interest.

\section{References}

Abela, M. (2004). Solidarity and religion in the European Union: A comparative sociological perspective. http://staff.um.edu.mt/ aabe2/EDRC Abela.pdf

Allard, J., Davidson, C., \& Matthaei, J. (2008). Solidarity economy: Building alternatives for people and planet. ChangeMaker Publications. https://doi.org/10.1177/0486613409350429

Arruda, M. (2004). ¿Qué es la Economía solidaria? el renacimiento de una sociedad humana matrística. Economía solidaria, 27, 71-75. https://www.ecologiapolitica.info/novaweb2/wp-content/uploads/2019/10/027_Arruda_2004.pdf

Asamblea General de la Union Europea. (2015). Transformar nuestro mundo: la Agenda 2030 para el Desarrollo Sostenible. https://www.equidad.org.mx/pdf/2_Agenda 2030 Desarrollo Sostenible.pdf

Banaszak, I. (2008). Determinants of successful cooperation in agricultural markets: Evidence from producer groups in Poland. In G. Hendrikse, M. Tuunanen, J. Windsperger, \& G. Cliquet (Eds.), Contributions to management science. Strategy and governance of networks (pp. 27-46). Physica-Verlag HD. https://doi.org/10.1007/978-3-7908-2058-4_3

Berman, Y., \& Phillips, D. (2004). Indicators for social cohesion. Paper submitted to the European Network on Indicators of Social Quality of the European Foundation on Social Quality, Amsterdam. https://citeseerx.ist.psu.edu/viewdoc/download?doi=10.1.1.598.8066\&rep=rep1\&type=pdf

Bots, P. W. G., Barreteau, O., \& Abrami, G. (2010). Simulation of solidarity in a resource sharing situation. https://hal.archives-ouvertes.fr/hal-00468543

Botton, C. L. de, \& Joanpere, C. M. (2015). Exploring approaches for measuring solidarity (SOLIDUS Concept paper 8.1). http:// solidush2020.eu/outcomes/

Chuang, Y. C., Chuang, K. Y., \& Yang, T. H. (2013). Social cohesion matters in health. International Journal for Equity in Health, 12(1), 87. https://doi.org/10.1186/1475-9276-12-87

Dutta, S., \& Lanvin, B. (2020). The network readiness index 2020. Accelerating digital transformation in a post-COVID Global economy. Portulans Institute. https://networkreadinessindex.org/wp-content/uploads/2020/10/NRI-2020-Final-Report-October2020.pdf

Eurostat. (2021). Database. Retrieved March 3, 2021, from https://ec.europa.eu/eurostat/data/database

Friedman, E. A., \& Gostin, L. O. (2017). From local adaptation to activism and global solidarity: Framing a research and innovation agenda towards true health equity. International Journal for Equity in Health, 16(1), 18. https://doi.org/10.1186/s12939-016-0492-8

Global Footprint Network. (2020). Open source platform. https://data.footprintnetwork.org/?_ga=2.217329110.1105050611. 1616685999-468294695.1614675380\#/

Hrynevych, O., \& Goncharenko, O. (2018). Enfoque científico y metodológico para evaluar el nivel de solidaridad de la economía. In Conference: XXXII Congreso Internacional de Economía Aplicada, ASEPELT 2018. Huelva, Spain. https://www.researchgate.net/publication/332269517

Kawano, E. (2013). Social Solidarity Economy: Toward convergence across continental divides. Unrisd.Org. https://www.unrisd. org/thinkpiece-kawano\&cntxt=F7711\&cookielang=es

Lee, S. (2020). Role of social and solidarity economy in localizing the sustainable development goals. International Journal of Sustainable Development and World Ecology, 27(1), 65-71. https://doi.org/10.1080/13504509.2019.1670274

Lichterman, P. (2015). Religion and social solidarity. In L. Hustinx, Von J. Essen, J. Haers, \& S. Mels (Eds.), Nonprofitandcivilsocietystudies. Religionandvolunteering (pp. 241-261). Cham: Springer. hhttps://doi.org/10.1007/978-3-319-04585-6_12

Little, T. D. (2013). Longitudinal structural equation modeling. The Guilford Press.

Lyson, T. A. (2012). Civic agriculture: Reconnecting farm, food, and community. Tuffs University Press.

Madarasz, D., Skriniarova, K., \& Bandlerova, A. (2013). Agricultural cooperatives and their impact on the regional development in the Nitra Region. Journal of Economy \& Society, 2013(2-3), 115-126. https://doi.org/10.21637/GT.2013.2-3.07.

Malak-Rawlikowska, A., Majewski, E., Wąs, A., Borgen, S. O., Csillag, P., Donati, M., Freeman, R., Hoàng, V., Lecoeur, J.-L., Mancini, M. C., Nguyen, A., Saïdi, M., Tocco, B., Török, Á., Veneziani, M., Vittersø, G., \& Wavresky, P. (2019). Measuring the economic, environmental, and social sustainability of short food supply chains. Sustainability, 11(15), 4004.

https://doi.org/10.3390/su11154004 
Miller, E. (2013). Community economy: Ontology, ethics, and politics for radically democratic economic organizing. Rethinking Marxism, 25(4), 518-533. https://doi.org/10.1080/08935696.2013.842697

Mozas Moral, A. (2019). Contribución de las cooperativas agrarias al cumplimiento de los objetivos de desarrollo sostenible. Especial referencia al sector oleicola. CIRIEC-España. http:/www.ciriec.uliege.be/wp-content/uploads/2019/09/contribucion-de-las-cooperativas-agrarias-al-cumplimiento-de-los-objetivos-de-desarrollo-sostenible-especial-referencia-al-sector-oleicola.pdf

Quiroz-Niño, C., \& Murga-Menoyo, M. Á. (2017). Social and solidarity economy, sustainable development goals, and community development: The mission of adult education \& training. Sustainability, 9(12), 2164. https://doi.org/10.3390/su9122164

Ratcliffe, P., \& Newman, I. (2011). Promoting social cohesion: Implications for policy and evaluation. Bristol University Press, Policy Press. https://doi.org/10.2307/j.ctt9qgw9s

Reintjes, C. (2004). La economía solidaria: innovación y transformación de la sociedad y de la economía, construyendo una verdadera democracia social, política y económica. Ecología politica, 27, 63-69.

Reyes, B. (2005). Designing indicators for the solidarity economy. [Discussion paper]. Indicators Workshop meeting in Dakar. Dakar. https://base.socioeco.org/docs/doc-7418_en.pdf

Roy, A. Le, \& Ottaviani, F. (2016). Du capital social à la soutenabilité sociale: enseignements d'une démarche locale de construction d'indicateurs de bien-être soutenable [Social capital to social sustainability: Lessons from a construction of sustainable territorial social indicators]. Développement Durable et Territoires, 7(2), 11303. https://doi.org/10.4000/developpementdurable.11303

Svendsen, G. L. H., \& Svendsen, G. T. (2000). Measuring social capital: The Danish co-operative dairy movement. Sociologia Ruralis, 40(1), 72-86. https://doi.org/10.1111/1467-9523.00132

United Nations Research Institute for Social Development. (2018). Measuring the scale and impact of social and solidarity economy. https://www.unrisd.org/ib9

United Nations Research Institute for Social Development. (2019). UNTFSSE International Conference: Implementing the Sustainable Development Goals: What role for social and solidarity economy? https://www.unrisd.org/80256B3C005BCCF9/ (httpPublications)/09940E13E1EC57B48025848D003080C5?OpenDocument

United Nations Research Institute for Social Development. (2021). Guidelines for local governments on policies for social and solidarity economy. https://www.unrisd.org/80256B3C005BCCF9/(httpPublications)/EC42DDF4C2DDA1208025866B00481C54?OpenDocument

Utting, P. (2018). Achieving the sustainable development goals through social and solidarity economy: Incremental versus transformative change (UNRISD Knowledge Hub Working Paper No. 1). http://www.unrisd.org/80256B3C005BCCF9/(httpPublications)/DCE7DAC6D248B0C1C1258279004DE587?OpenDocument\&cntxt=66637\&cookielang=fr

Utting, P., \& Dijk, N. Van. (2014). Social and solidarity economy is there a new economy in the making? Potential and limits of social and solidarity economy (UNRISD Occasional Paper 10). www.unrisd.org/funding

Villalba-Eguiluz, U., Egia-Olaizola, A., \& Pérez De Mendiguren, J. C.(2020). Convergences between the social and solidarity economy and sustainable development goals: case study in the Basque Country. Sustainability, 12(13), 5435. https://doi.org/10.3390/su12135435 